\title{
EDUCAÇÃO LITERÁRIA E EXPRESSÃO/EDUCAÇÃO DRAMÁTICA/TEATRO: ALGUMAS SINERGIAS EM CONTEXTO ACADÊMICO
}

\author{
Carla Pires Antunes ${ }^{1}$ \\ Maria Flor Dias ${ }^{2}$ \\ Sara Reis da Silva ${ }^{3}$
}

\begin{abstract}
Resumo: Neste breve ensaio divulga-se e reflete-se acerca de um projeto interdisciplinar, a dinamizar no período de 2013-2016, no âmbito da Licenciatura em Educação Básica, no Instituto de Educação da Universidade do Minho (Braga, Portugal). Procura-se acentuar a transversalidade da língua portuguesa, materializada em textos literários, mas também alargar a própria cultura artística, nomeadamente no domínio da criação e fruição teatrais. Numa primeira fase, é proposto conhecer a cultura literária dos alunos da licenciatura para, posteriormente, no contexto de disciplinas como a "Literatura para a Infância e Juventude" e a "Expressão e Educação Dramática", alargar o contacto com modos literários cuja receção é, aparentemente, menos generalizada (poético e dramático/teatral); desenvolver dimensões fonológicas e de interpretação inerentes a contextos de dizer e de oralidade (narração, formas poético-líricas e texto dramático); perceber como a leitura poderá contribuir para a melhoria da capacidade de desconstrução de textos e, consequentemente, para a formação de futuros cidadãos ativos na leitura do texto-mundo.
\end{abstract}

Palavras-chave: Educação literária; Educação dramática; Texto dramático; Formação de professores.

\section{LITERARY EDUCATION AND THEATRICAL/DRAMA EDUCATION: A FEW SYNERGIES WITHIN AN ACADEMIC CONTEXT}

\begin{abstract}
Summary: This brief essay we aim to share and reflect on the interdisciplinary project, which took place between 2013 and 2015, as part of the degree in Basic Education at the Institute of Education of the University of Minho (Braga, Portugal). Not only do we seek to highlight how transversal the Portuguese language is, embodied in literary texts, but also contribute to the artistic culture itself, namely through the theatrical creation. In the initial stage, we intend to get acquainted with the students' literary culture in order to expand their contact with less widespread literary genres (poetry and drama), within the context of subjects, such as Children and Youth Literature and Drama Education; to develop phonological and interpretative dimensions related to popular expressions and spoken interaction (narration, forms of lyric poetry and dramatic text); to understand how reading may help to develop text analysis skills, thus, shaping active citizens of the future who are capable of relating personal interpretations with their own understanding of the world.
\end{abstract}

Keywords: Literary education; Drama education; Drama text; Teacher training.

\footnotetext{
${ }^{1}$ Doutorada em Educação Dramática. Professora Auxiliar no Instituto de Educação da Universidade do Minho, na área de Educação e Expressão Dramática/Teatro, no Departamento de Teoria da Educação e Educação Artística e Física. Email: cmfapa@ie.uminho.pt

${ }^{2}$ Doutorada em Estudos da Criança, na Área de Especialização de Educação Dramática, pela Universidade do Minho e investigadora do Centro de Investigação em Estudos da Criança (CIEC). É Professora Auxiliar no Instituto de Educação da Universidade do Minho, na área de Educação e Expressão Dramática/Teatro, no Departamento de Teoria da Educação e Educação Artística e Física. Email: flor@ie.uminho.pt

${ }^{3}$ Doutorada em Estudos da Criança pela Universidade do Minho, na Especialidade de Literatura para a Infância. Desenvolve a sua docência e a sua investigação na área dos estudos literários e, em particular, da literatura de potencial receção infanto-juvenil, no Instituto de Educação da Universidade do Minho, no Departamento de Estudos Integrados de Literacia, Didática e Supervisão. Integra a equipa responsável pelo projeto Gulbenkian Casa da Leitura (www.casadaleitura.org). Email: sara silva@ie.uminho.pt
}

Momento: diálogos em educação, E-ISSN 2316-3100, v. 26, n. 1, p. 161-176, jan./jun. 2017 


\title{
INTRODUÇÃO
}

Perspetivada como ato alicerçante na formação integral do Homem, a literatura/a leitura, em particular, a leitura literária, paralelamente ao contato/conhecimento com/de outras artes, é, cada vez mais, encarada, de forma consensual, como meio de realização individual e cultural, como fator de socialização e de reconhecimento social.

Assim sendo, a leitura não pode, pois, ter apenas um objetivo utilitário, nem ser alvo de uma instrumentalização que passa, não raras vezes, por estratégias de abordagem que recorrem ao texto literário como mero e pobre trampolim para o tratamento de conteúdos formais de áreas de conhecimento como as Ciências da Natureza ou a Matemática, por exemplo. Efetivamente, "Una cosa es utilizar textos literarios para ejercitar y perfeccionar el lenguaje y otra distinta es intentar que, a través de los textos, los alumnos vayan adentrándose en las técnicas, avancen en su propia educación literaria y empiecen a amar la literatura.” (GÓMEZ-VILLALBA apud LÓPEZ MOLINA, 2004, p. 11). Nesta linha, Barthes apud Compagnon (2010: 9), por exemplo, condena todos os usos supletivos - pedagógico/ ideológico e ou mesmo; linguístico - da literatura, preconizando que "A literatura não permite caminhar, mas permite respirar." Nesse contexto, Johnson apud Compagnon (2010: 45) considera, também, que "A única finalidade da literatura consiste em tornar os leitores capazes de desfrutar melhor da vida, ou de a suportar melhor". E, em Para que Serve a Literatura?, Compagnon (idem, p. 47) não hesita em afirmar que

\begin{abstract}
A literatura desconcerta, incomoda, confunde, desorienta mais do que os discursos filosófico, sociológico ou psicológico, porque apela às emoções e à empatia. Deste modo, ela percorre regiões da experiência que os demais discursos descuram, mas que a ficção reconhece ao pormenor. [...] A literatura liberta-nos dos nossos modos artificiais de pensar a vida - a nossa e a dos outros.
\end{abstract}

Multiplicam-se, na verdade, as reflexões partilhadas nesse sentido por intelectuais/pensadores irrecusáveis, todas elas redundando no elogio profundo da literatura, da leitura e do livro. Se, por um lado, não são raras as vezes em que nos confrontamos com uma visão da leitura como uma atividade séria, tomando-se, com facilidade, a palavra "séria" como sinónimo de "monótona", "aborrecida" ou "antissocial", por outro lado, nas últimas décadas, a leitura ${ }^{4}$ surge, frequentemente, conotada com as ideias de jogo ou de atividade

\footnotetext{
${ }^{4}$ Entendido pluralmente, o termo "leitura" merece atenção especial no contexto particular deste estudo. Ler é uma tarefa complexa, que reclama o funcionamento articulado de todo o sistema cognitivo. Além disso, a motivação para este processo de apreensão de um determinado código encontra-se muito dependente das experiências de vida e do próprio contexto ou meio em que vive o leitor. A autonomia da leitura consiste em conseguir ler e compreender, voluntariamente e sem dificuldades, textos de qualquer tipo (informativo, literário, ensaístico, etc.), emitindo juízos críticos e confrontando-os com a sua experiência. A competência de leitura e a competência literária intimamente associadas, consolidam-se ao longo da vida e mediante uma "acumulação" de Momento: diálogos em educação, E-ISSN 2316-3100, v. 26, n. 1, p. 161-176, jan./jun. 2017
} 
lúdica, motivadora de prazer. Noções mais ou menos consensuais, em especial no que diz respeito às práticas de mediação de leitura com crianças e jovens, a verdade é que ler não é um jogo puro e simples, mas um exercício cognitivo e de compreensão de indiscutível complexidade, um processo no qual se conjugam o pensamento, a memória e, naturalmente, se nos reportarmos aos primeiros leitores, a ludicidade. A "construção" de um leitor, entendido aqui como aquele que lê autónoma, voluntaria e/ou livremente documentos distintos, em situações diversas, e é capaz de problematizar o que leu, é determinada pelas experiências de leitura (motivadoras ou desanimadoras) que este possui, desde tenra idade, ocorrendo estas em dois contextos fundamentais: a família e a escola.

No ensaio "Dimensão Pedagógica da Leitura", Herdeiro (1980), não desvalorizando o papel determinante do contexto familiar no contacto precoce e significativo com os livros e com a leitura, preconiza que cabe à escola, como principal instituição educativa:

Repensar o valor pedagógico da leitura numa formação integral, desenvolver uma prática de orientação e promoção da leitura, inserida num programa educativo que valorize a capacidade imaginativa e criadora e o poder de análise e de crítica, e ainda dinamizar uma reflexão sobre a importância do livro como instrumento de cultura (HERDEIRO, 1980, p. 43).

Com efeito, o livro sobressai como instrumento insuperável no processo contínuo e infinito de formação afetiva, moral e estética, na estruturação intelectual ou do pensamento, bem como de competências de compreensão e expressão oral e escrita.

Aliado à prática conversacional com a criança e ao hábito de lhe contar histórias diariamente desde os primeiros anos de vida, o livro infantil é um dos melhores instrumentos de que dispomos para proporcionar aos mais novos a possibilidade de se tornarem seres humanos mais livres e cultos, solidários e críticos, graças a esse gradual domínio da palavra e da competência literária que a leitura propicia (GOMES (s/d, p. 5).

\section{EDUCAÇÃO LITERÁRIA E AS METAS CURRICULARES DE PORTUGUÊS}

Desde 10 de Agosto de 2012, data da homologação das Metas Curriculares de Português, encontra-se regulamentado, do $1^{\circ}$ ao $3^{\circ}$ ciclos, o domínio designado como "Educação Literária", expressão que deve ser entendida como "a implementação de uma metodologia que procure dotar o leitor e futuro mediador de um conjunto de saberes culturais, literários e sociais que forneçam as "enciclopédias" e os intertextos individuais para descobrir modelos, esquemas, convencionalismos, símbolos, mitos, acontecimentos históricos..., uma

leituras significativas. Na verdade, o "intertexto leitor" ou esse conjunto de leituras, numa situação de interpretação textual, entram em diálogo e interatuam, ampliando as possibilidades de descodificação. (MENDOZA FILLOLLA, 2001) 
reação individual perante uma obra literária.” (ROIG RECHOU, 2008, p. 333) (Trad. nossa). No referido documento oficial, pode ler-se:

Foi criado, de acordo com as melhores práticas internacionais, o domínio da Educação Literária, que recebeu vários descritores que antes estavam dispersos por diversos domínios. Tal corresponde a uma opção de política da língua e de política de ensino. Argumenta-se, de um lado, que a Literatura, como repositório de todas as possibilidades históricas da língua, veicula tradições e valores e é, como tal, parte integrante do património nacional; do outro, que a Educação Literária é imprescindível para uma forma de cidadania mais complexa e consciente, contribuindo para a formação completa do indivíduo. [...] Neste âmbito, ainda, foi criada uma lista de obras e textos para leitura anual, válida a nível nacional, garantindo assim que a escola, a fim de não produzir diferenças socioculturais exteriores, assume integralmente a defesa de um currículo mínimo para todos os alunos que frequentam o Ensino Básico. [...] Para a promoção da leitura autónoma, foram mantidas as listagens do Plano Nacional de Leitura (PNL). (BUESCU et al., 2012 , p. 5-6)

A partir da estipulação de listas de textos e obras "para ler e ouvir ler" - sete, no seu total, para cada ano de escolaridade -, inculcam-se, tendo por base descritores de desempenho, práticas progressivas e de continuidade de contacto com a literatura, materializada em discursos contemporâneos e do passado, de autores portugueses/lusófonos e estrangeiros, de modos/géneros/subgéneros diversos (integrando, portanto, textos poéticos, narrativos e dramáticos) e de correntes/tendências literárias variadas.

Uma análise atenta e em pormenor deste referencial permite, portanto, pressupor que aí se pretende: defender o atrativo da obra literária em si mesma e/ou em diálogo com outras formas de arte; sugerir a aceitação de interpretações e olhares pessoais sobre o texto literário; veicular valores formativos (humanizadores) inerentes à leitura literária; e preconizar/implementar um conjunto de leituras significativas, em muitos casos articuladas com outras formas de expressão artística.

\begin{abstract}
A educação literária (ou seja, a aprendizagem e o treino da leitura literária, indissociáveis de um progresso na quantidade e na qualidade das obras lidas) é um moroso processo que se desenrola ao longo de toda a escolaridade e que pode e deve ter seguimento noutros contextos formais e não formais. Um processo reconhecidamente complexo, se atendermos à peculiar natureza do texto literário, à pluralidade dos seus sentidos e dos seus recursos técnico-expressivos, ao seu elevado grau de estruturação e aos desafios que coloca à inteligência e à sensibilidade do leitor, no trabalho de leitura e de interpretação (MACEDO e GOMES, 2013, p. 79).
\end{abstract}

\footnotetext{
${ }^{5}$ As listas de obras estipuladas pelo Plano Nacional de Leitura, da responsabilidade do Governo Português, dizem respeito ou são indicadas para os diferentes níveis de escolaridade, contemplando uma considerável diversidade de títulos. Muito embora integrem a referência aos principais autores de âmbito nacional e internacional - clássicos incluídos - algumas das obras aí patentes são de qualidade bastante discutível. Além disso, a sua adequação ao tipo de leitor para o qual surgem indicadas é, por vezes, também questionável. Sugerese uma visita a http://www.planonacionaldeleitura.gov.pt/index1.php
} 


\section{EDUCAÇÃO LITERÁRIA E COMPETÊNCIAS INTERARTÍSTICAS: TEXTO DRAMÁTICO E TEATRO}

$\mathrm{Na}$ realidade, a educação literária não se concretiza de forma desligada de outras competências, tais como, por exemplo, a competência intertextual (capacidade de "cruzamento" ou inter-relacionamento de textos) e competência interartística (diálogo da literatura, enquanto arte, com outras artes, como a música, a pintura ou o teatro).

A este título, e recentrando a atenção no documento das Metas Curriculares de Português, observa-se, por exemplo, a contemplação de títulos de leitura/abordagem obrigatória que reúnem não apenas um texto literário de qualidade, mas também um suporte audio/musical. São os casos das obras Bichos, Bichinhos e Bicharocos, de Sidónio Muralha, indicada para o $2^{\circ}$ ano, e de A Arca do Tesouro, Um Pequeno Conto Musical, de Alice Vieira, apontada para o $3^{\circ}$ ano. O texto dramático, guardando em si o "espetáculo" ou a representação teatral em potência, cuja leitura metódica surge apenas contemplada a partir do $3^{\circ}$ ano de escolaridade, é também incluído no documento oficial em questão. Esta integração pode, igualmente, ser entendida como um meio de promoção do contato interartístico e de uma possível formação/educação artística. O mesmo poderíamos concluir das propostas de leitura de obras que possuem edições profusamente ilustradas, evidenciando um registro visual estimulante que abre também o caminho para uma "educação pela arte". Referimo-nos, por exemplo, A História de Pedrito Coelho, escrito e ilustrado por Beatrix $\operatorname{Potter}^{6}$ ( $1^{\mathrm{o}}$ ano), Estranhões \& Bizarrocos, de José Eduardo Agualusa, com ilustrações/grafismo do designer Henrique Cayatte $^{7}$ ( $2^{\circ}$ ano), A Cor das Vogais, de Vergílio Alberto Vieira, com ilustrações de Teresa Lima ${ }^{8}$ ( $3^{\circ}$ ano), e $A$ Maior Flor do Mundo, de José Saramago, com ilustrações de João Caetano (2001), obra, aliás, galardoada com o Prémio Nacional de Ilustração.

Mesmo nos domínios de referência, nos objetivos e nos descritores de desempenho a partir dos quais se encontram estruturadas as Metas Curriculares (2012), são percetíveis percursos de abordagem e de ensino-aprendizagem que preveem uma (desejável/exigível) articulação entre áreas. A título exemplificativo atente-se apenas no programa do $3^{\circ}$ ano de escolaridade, ano no qual são introduzidas a leitura e análise do texto dramático, e onde se avaliam as potencialidades formativas inerentes à conjugação sustentada e refletida de descritores de desempenho como: no domínio da oralidade, "usar a palavra com um tom de

\footnotetext{
${ }^{6}$ A autora/ilustradora inglesa Beatrix Potter (1866-1943) é considerada como uma das pioneiras na criação artística do álbum narrativo para as primeiras idades.

${ }^{7}$ Prémio Gulbenkian de Ilustração em 2001.

${ }^{8}$ Prémio Nacional de Ilustração em 2006.

Momento: diálogos em educação, E-ISSN 2316-3100, v. 26, n. 1, p. 161-176, jan./jun. 2017
} 
voz audível, boa articulação e entoação e ritmo adequados" (ibidem: 53) e, no domínio da Educação Literária, "Ler em voz alta, após preparação da leitura”, "Manifestar sentimentos, ideias, pontos de vista suscitados pelas histórias lidas" e "Dramatizar textos (treino da voz, dos gestos, das pausas, da entoação e da expressão facial" (ibidem: 56), entre outros.

De facto, no contacto e na análise do texto dramático - entendido como um dos modos naturais da literatura -, congrega-se uma pluralidade de elementos interrelacionados.

\begin{abstract}
Importa conhecer a ideia geral do texto, os seus antecedentes e consequentes, o seu sentimento dominante ou a sua progressão. Como no conto ou no romance, convém estudar o diálogo e a sua evolução e gradações psicológicas; como nas composições oratórias, é necessário avaliar do valor convincente, da naturalidade e vigor dos discursos; tal como nas composições poéticas, deve olhar-se também ao valor sentimental dos monólogos e à sua influência na acção ulterior; e, se não há-de esquecer-se o valor dramático total do texto, por isso mesmo se não deve pôr de parte o estudo dos caracteres, através das suas reacções e preferências (MARQUES, 1972, p. 68).
\end{abstract}

\title{
EDUCAÇÃO LITERÁRIA E EXPRESSÃO DRAMÁTICA NO CONTEXTO ACADÉMICO: UM PROJETO INTERDISCIPLINAR \\ O ESTADO DO CONHECIMENTO LITERÁRIO E DRAMÁTICO DOS ESTUDANTES
}

Nos últimos anos, a nossa experiência docente/investigativa em contexto académico tem-nos levado a concluir que a formação literária e artística, em geral, dos nossos alunos da Licenciatura em Educação Básica, futuros profissionais de educação/mediadores de leitura, mesmo numa fase que se pode considerar já avançada dos estudos/nos estudos literários, é manifestamente débil, evidenciando níveis de competência literária muito distintos/diferenciados, em alguns casos, até, constrangedores quanto, por exemplo, ao intertexto leitor. De facto, como defende, em termos genéricos, Cerrillo (2004), a propósito de muitos dos novos leitores do século XXI, a grande maioria dos atuais discentes portugueses do ensino superior são "leitores com experiências infantis marcadas pela televisão, os jogos eletrónicos, o jogo solitário, as histórias Disney" (idem, p. 37). Por outras palavras, revelam ser detentores de um parco património literário, que se restringe, em muitos casos, às leituras acumuladas ao longo do seu percurso escolar pré-universitário ou às obras de leitura metódica previstas nos Programas da disciplina de Língua Portuguesa/Português.

Daí que, no contexto da Licenciatura em Educação Básica e em diversas Unidades Curriculares (UC), se proponha o estudo sistemático de textos narrativos, poéticos e dramáticos, colocando os futuros profissionais de educação perante um conjunto mais ou menos vasto de obras assinadas por autores diversos, visto que encaramos como fundamental que estes, enquanto mediadores do contato infanto-juvenil com os livros e com a leitura; 
reconheçam a sua importância ou o seu lugar na educação linguística, literária e estética ${ }^{9}$. São, neste contexto, decisivos quer o conhecimento de modos/géneros ou textos plurais ${ }^{10}$, quer a aquisição de competências não só ao nível da seleção ${ }^{11}$, mas também do trabalho continuado, ao nível da mediação/animação de leitura, a partir de distintas modalidades literárias e tipologias textuais, em função das necessidades associadas ao desenvolvimento dos seus próprios discentes.

\section{O PROJETO: CONCEPTUALIZAÇÃO, OBJETIVOS E CONSIDERAÇÕES}

Genericamente sustentado no quadro teórico-conceptual acima exposto e num outro referencial de cariz teórico-prático (SPOLIN, 1992; KOUDELA, 1998; FAZENDA, 2001; NAVES, 2004; BORTOLIN, 2010; MATEO, 2010; VARLEY, 2011), demos início a um projeto que se reveste de uma dimensão interdisciplinar, procurando não apenas acentuar a transversalidade da língua portuguesa, mas também a própria cultura e educação artística.

O projeto envolve o universo de alunos matriculados nesta edição da Licenciatura em Educação Básica que frequentaram o triénio 2013-2016 da referida Licenciatura, num total de cerca de 200 estudantes. Estabelece, como objetivo principal, estudar as dimensões da educação literária e artística na formação inicial de professores do $1^{\circ}$ ciclo do ensino básico e educadores de infância. Neste sentido, inicialmente, propomo-nos conhecer as práticas e os hábitos de leitura dos alunos para, posteriormente, e designadamente no âmbito de UC como Literatura para a Infância e a Juventude (LIJ) e Expressão Dramática (ED), desenvolver estratégias multidisciplinares de leitura e de animação de leitura; alargar o contacto com modos literários cuja receção é aparentemente menos generalizada (poético e dramático/teatral); desenvolver dimensões fonológicas inerentes a contextos de dizer e de oralidade (narração, formas poético-líricas e texto dramático); conceber e desenvolver, na interface curricular entre a Educação e Expressão Dramática e a Educação Literária, pequenas criações teatrais; explorar estratégias cinético-dramáticas (nomeadamente o teatro de formas animadas) potencializadoras da leitura e da interpretação de textos e, consequentemente, da formação de alunos leitores; adquirir competências no domínio da abordagem das formas poético-líricas em contexto educativo; propiciar situações de fruição estética do texto dramático e teatral; perceber como a leitura poderá contribuir para a melhoria da capacidade

\footnotetext{
${ }^{9}$ Sobre este assunto, vide Gomes (2004).

${ }^{10}$ Gomes (2014:14-15) diferencia oito géneros no domínio da ficção para crianças e jovens, destacando, ainda, outras obras que, situando-se fora deste âmbito, possuem também importância na formação de leitores.

${ }^{11}$ Note-se que a diversidade (qualitativa e quantitativa) da oferta editorial destinada aos jovens leitores exige, cada vez mais, do mediador uma constante atualização e o conhecimento de critérios de seleção específicos.

Momento: diálogos em educação, E-ISSN 2316-3100, v. 26, n. 1, p. 161-176, jan./jun. 2017
} 
de interpretação de textos e, consequentemente, para a formação de futuros cidadãos ativos na leitura do texto-mundo.

Dada a natureza do estudo e dos objetivos definidos, consideramos como opção metodológica a investigação-ação. Neste primeiro ciclo da investigação, convocámos a observação e o inquérito por questionário, como instrumentos de recolha de dados e de diagnóstico da situação, e as notas de reflexão, como instrumento de avaliação.

Definidas as motivações, articulados os objetivos comuns, considerados os limites metodológicos dos domínios de conhecimento envolvidos (Literatura para a Infância e Juventude (LIJ) e Expressão Dramática (ED)), impunha-se, na fase de diagnóstico, tatear o grau de competência literária e de fruição artística dos alunos.

\section{PRINCIPAIS RESULTADOS (PRIMEIRO ANO)}

Um conjunto de questões, lançadas sobre preferências literárias, memórias de leitura, práticas de fruição literária e teatral, representações do professor e do educador sobre competências inerentes à ação de contar histórias, bem como o conhecimento de obras, autores e ilustradores de referência pelos formandos, configurou o primeiro inquérito por questionário (v. Apêndice $1-1^{\circ}$ ano Questionário Educação Artística e Literária). A análise do questionário revelaria uma cartografia muito ensombrada, em particular pela ausência de conhecimento, por parte dos estudantes, do universo da literatura para a infância: $86 \%$ dos inquiridos assume conhecer os títulos da atual oferta editorial de Literatura para Infância; contudo, $83 \%$ admite não ter lido qualquer texto literário dirigido à infância. Dos textos literários do universo infantil mais recordados pelos discentes, $74 \%$ inscrevem-se na tipologia das histórias tradicionais ouvidas na sua infância. Desse universo, 52\% dos estudantes admitem ter visto, frequentemente, filmes de animação que recriavam grande parte dos contos tradicionais infantis.

Os resultados destacam ainda, que os estudantes não têm hábitos de participação em atividades literárias e artísticas. Relativamente à frequência com que vão ao teatro, a maioria dos alunos, $57 \%$, salienta que raramente vai ao teatro; $21 \%$ refere ter ido ao teatro algumas vezes; enquanto, em ex aequo, outros $21 \%$ afirmam nunca terem ido ao teatro. Ainda relativamente à fruição teatral, $90 \%$ dos estudantes dizem ter assistido a espetáculos teatrais baseados em textos de autores de leitura obrigatória indicados nos Programas da disciplina de Língua Portuguesa/Português. 
Enquanto público de espetáculos dirigidos à infância 36\% dos alunos afirmam nunca ter assistido, enquanto $43 \%$ referem raramente ter assistido a espetáculos dessa natureza.

Quanto às suas experiências relacionadas com o "fazer teatro", 48\% dizem que nunca fizeram teatro e $36 \%$ dizem tê-lo feito algumas vezes; $9 \%$ muito raramente e só $7 \%$ dizem ter feito teatro frequentemente. Dos 52\% de estudantes que alguma vez fizeram teatro, fizeram-no na escola, sendo que 33\% consideram a experiência como "interessante" e "gratificante" e 17\% como "boa" e "útil".

Contudo, os resultados da análise revelam, sobretudo, que os estudantes têm pouco interesse em ler, especialmente, leitura literária. Quando questionados sobre se "alguma vez leu um texto dramático", $67 \%$ referem ter lido algumas vezes e $26 \%$, referem raramente ter lido. No que diz respeito aos títulos das obras lidas, tal como já, anteriormente, mencionado, destacam-se, com 100\% das respostas, as obras de leitura obrigatória referidas nos Programas da disciplina de Língua Portuguesa/Português.

\section{ESTRATÉGIAS DE TRABALHO EM CONTEXTO DE SALA DE AULA (PRIMEIRO ANO)}

Identificado o estado da arte, importava explicitar conexões curriculares, eleger, na fronteira dos dois domínios de saber, obras e géneros literários, priorizar ações, de modo a que a intervenção a desenvolver no âmbito da Expressão Dramática operasse com conteúdos comuns e fundamentais dos domínios disciplinares em presença. Esta preocupação com a integração curricular implícita; quer na transversalidade da língua portuguesa, quer na definição de objetivos e de "indutores" (LANDIER e BARRET, 1999) comuns (os textos), esteve sempre latente nas atividades que as docentes responsáveis pelas UC têm desenvolvido, conquanto, quer a lógica escolar, no que concerne à organização do currículo e do calendário escolar, quer a lógica da própria academia dificultem, muitas vezes, a possibilidade de diálogos entre disciplinas.

Os critérios de seleção e distribuição dos modos literários e das obras de referência, a explorar ao longo do triénio da Licenciatura, seguiram de perto as orientações programáticas das UC envolvidas (v. http://www.uminho.pt/estudar/oferta-educativa/cursos/licenciaturas-e-

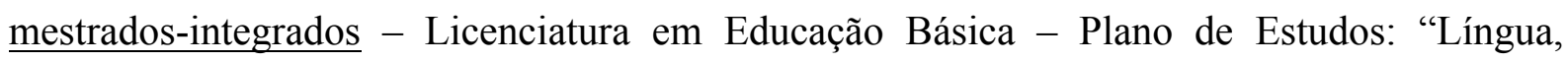
Textualidade Literária e Estratégias Interpretativas"; "Expressão Dramática e Movimento"). Assim, o modo poético seria abordado, em ambas as UC, no $1^{\circ}$ ano; o conto e o modo dramático no $2^{\circ}$ ano; enquanto a exploração de formas e estratégias de dinamização da leitura 
tomariam lugar no plano da UC de Didática do $3^{\circ}$ ano da formação inicial de professores e educadores.

Iniciámos a intervenção em Expressão Dramática retomando com os alunos do $1^{\circ}$ ano o acervo poético anteriormente trabalhado na UC de Língua, Textualidade Literária e Estratégias Interpretativas. Do conjunto das obras e dos autores propostos ${ }^{12}$ selecionou-se um outro punhado de textos. Os poemas, destacados das obras, foram sendo individualmente trabalhados. Em contexto da sala de aula, privilegiámos a aproximação intuitiva, deixando aos alunos tempo para a escolha individual dos "seus poemas". Procurávamos, ao desencadear em simultâneo, aspetos cognitivos, afetivos e expressivos, levar os alunos a vivenciar sensibilidades e a reconhecer que a forma poética pode conformar a pessoa humana na sua inteireza.

No trilho da educação literária e artística, procurámos descolar a voz do simples plano fónico para o plano gestual e interpretativo, ancorando-a, nesta posição, na categoria textual. Para isso, chamámos ao processo a dimensão lúdica e prazerosa da descoberta da própria voz, como instiga Varley (2011: 23), a propósito do dizente no seu encontro com a possibilidade de diferentes técnicas do dizer: "I believe that a thousand ways of breathing and singing exist and that each person has to recognize her own".

Nesta procura das relações entre as sonoridades da voz, o gesto, a palavra, os seus sentidos e interpretações, jogaram-se possibilidades várias, combinações entre as qualidades físicas (entoação, duração, intensidade, timbre, ritmo e volume) e psicológicas que o verbal oferece, numa pesquisa progressivamente plena de fisicalidade que amiúde se deixou atravessar pelo riso, pela surpresa e se deixou tocar pela emoção.

No processo de descoberta da sonorização da palavra, adotámos procedimentos diversificados, desde a exploração lúdica da acústica das palavras, o uso de trava-línguas e lengalengas, a exploração de onomatopeias, o uso do verso, do canto e de formas corais, a procura de associações inusitadas entre sentidos e voz, até à leitura por redundância ou por contraste. Instigámos ao despertar da perceção e sensibilidade sonoras, à descoberta de sonoridades ocultas, à distorção e invenção de outras, procurando que os alunos fizessem da voz um instrumento pessoal de expressão poética.

\footnotetext{
${ }^{12}$ Alice Vieira; Álvaro Magalhães; Eugénio de Andrade; João Manuel Ribeiro; João Pedro Mésseder; Jorge Sousa Braga; José António GOMES; José Jorge Letria; Luísa Ducla Soares; Mário Castrim; Maria Alberta Menéres; Matilde Rosa Araújo.

Momento: diálogos em educação, E-ISSN 2316-3100, v. 26, n. 1, p. 161-176, jan./jun. 2017
} 
No momento em que a voz, já mais desvelada, se fez gesto e a leitura corpo, para usar uma referência bartheana, o desejo do poema encenado ganhou materialidade.

"Imaginar a representação" (HAYMAN apud TURUEL, 1999) requereu dos alunos maior aprofundamento analítico e maior esforço de atenção e entrega à imaginação: para procurar sentidos no poema (sem matar a poesia), para imaginar espaços e presenças, para fazer a voz criar atmosferas, para acordar uma memória (cada vez escolarmente menos convocada e mais instalada na zona fugaz e de conforto da imagem), para partilhar emoções e interpretações que os textos pudessem ter acordado nas sucessivas leituras experimentadas pelos alunos.

Os diferentes poemas, destacados ou agrupados por temáticas (personagens/humanos/animais, objetos, números, ambiências, retratos, etc.) seriam objeto de exploração e encenação, gerando, no final, a apresentação de um conjunto de pequenos trabalhos de natureza performativa.

Para isso, importou preservar os sentidos que os alunos foram intuindo, dar conta da subtileza e tensão entre os jogos das diferentes linguagens (verbal, gestual e icónica) de modo a que, no ato da criação e da partilha, a poesia, jogada na descoberta de novos espaços (jardins e átrios), pudesse, ainda, e apesar de tudo, ressoar no silêncio e na memória de cada aluno. Neste abrir de espaços/corpos para "o dizer", o "diseur" e o ouvinte fusionaram-se num só sujeito. No adentrar desse trilho, procurámos com os alunos dar sentido à reflexão de Zumthor (1997, p. 157), quando sustenta que:

É pelo corpo que nós somos tempo e lugar: a voz o proclama emanação do nosso ser.
A escrita também comporta é verdade, medidas de tempo e espaço: mas o seu
objetivo último é delas se libertar. A voz aceita beneficamente sua servidão. A partir
desse sim primordial, tudo se colore na língua, nada mais nela é neutro, as palavras
escorrem, carregadas de intenção, de odores, elas cheiram ao homem e à terra (ou
aquilo com que o homem os representa.

\section{RESULTADOS (SEGUNDO ANO)}

Como referimos, o conto e o texto dramático foram os géneros literários abordados no $2^{\circ}$ ano da Licenciatura (v. http://www.uminho.pt/estudar/ofertaeducativa/cursos/licenciaturas-e-mestrados-integrados - Licenciatura em Educação Básica Plano de Estudos: "Expressão Dramática e Educação Musical", "Literatura para a Infância e Juventude"). Com o segundo questionário (v. Apêndice 2 - $2^{\circ}$ ano Questionário Educação Artística e Literária), pretendia-se obter informações relativas aos contributos da Licenciatura em Educação Básica para a formação literária dos futuros Professores e Educadores de 
Infância. $73 \%$ dos respondentes estabeleceram uma relação positiva entre a oferta do plano curricular da Licenciatura e sua Educação Literária, destacando o alargamento dos seus conhecimentos literários, no que respeita a autores, ilustradores, obras e géneros literários. 16\% evidenciaram a existência de diferentes Unidades Curriculares (Língua, Textualidade e Estratégias Interpretativas; Expressão Dramática; Estudos da Linguagem e Pedagogia da Infância; Literatura para Infância Juventude) que convocam diferentes dinâmicas e abordagens de textos, particularmente, ao nível da Literatura Infantil, contribuindo, também, desse modo, para a sua formação literária. Destaca-se de igual modo, a intencionalidade pedagógica que subjaz à seleção literária, a divulgação de autores e obras e, ainda, as dinâmicas relativas à compreensão, interpretação e dramatização dos textos, nomeadamente na sua relação com as didáticas específicas de cada área de conhecimento.

Quando questionados sobre a importância da Educação Dramática na Mediação de Leitura, 23\% dos estudantes salientaram o contributo da Educação Dramática no alargamento dos seus horizontes literários; 16\% destacaram a diversidade de estratégias da Educação Dramática na abordagem aos textos; 14\% consideraram que a Educação Dramática intervém no plano da comunicação e expressão, através do texto, trabalhando o domínio da voz, do corpo, da interpretação; em ex aequo, referiram os contributos da Educação Dramática no plano da formação pessoal e social, na medida em que esta potencializa o desenvolvimento do à-vontade, da segurança e da autoconfiança; $13 \%$ dos inquiridos consideraram que as pontes entre ambas as áreas de saber - Educação Dramática e Educação Literária - são indissociáveis, tendo a língua e o texto como elo de ligação entre elas.

\section{ESTRATÉGIAS DE TRABALHO EM CONTEXTO DE SALA DE AULA (SEGUNDO ANO)}

Em Expressão Dramática, e no que se refere ao conto, privilegiámos a vivência de formas lúdicas em torno do que definimos como "eixo do dizer". Na senda de Zumthor (1997), conduzimos o trabalho com o conto através da exploração da "voz, corpo, espaço e presença".

Para os futuros educadores e professores, ler e contar histórias, ou declamar poesia são práticas a inscrever no devir quotidiano da docência. Porém, para dominar os mecanismos da oralidade, para lidar com a arte de contar histórias, para chegar a descobrir a magia da voz, não basta saber dizer. Importa, sobretudo, saber ouvir: ouvir-se a si mesmo, ao outro, aos textos e ao próprio mundo. Como sustenta, ainda, Zumthor (ibidem: 86-87):

A voz implica o ouvido. Mas há dois ouvidos, simultâneos, uma vez que dois pares de ouvidos estão em presença um do outro, o daquele que fala e o do ouvinte. (...). 
O ouvido, com efeito, capta diretamente o espaço ao redor, o que vem de trás o que está na frente.

Gradativamente, no ato de contar histórias, os alunos foram instigados a se colocarem no lugar de sujeito da receção. Entre aquele que diz e aquele que ouve jogaram-se, então, papéis ativos e críticos que julgamos necessários incorporar no espetador literário - uma dimensão da formação que os futuros educadores e professores terão de chamar a si ao longo de uma formação necessariamente contínua.

Enquanto docentes, implicados em contextos de supervisão pedagógica, constatámos que o tempo dedicado no ensino básico ao texto dramático é, por comparação a outros modos literários, diminuto. Além disso, a abordagem habitual do texto dramático em sala de aula, não se diferencia nem se descentra da abordagem comum ao texto escrito. Ignora-se, assim, o facto de o teatro convocar, nas suas formas de expressão, signos de vários sistemas semióticos e de, também por isso, não ser, como sustenta Bobes Naves (1997: 13), “um género literário paralelo a los outros". Por esta razão, adotámos no projeto o conceito de texto dramático ou teatral na perspetiva de Bobes Naves (idem: 11- 12), ou seja:

Como el conjunto de la obra escrita y la obra representada (...) y distinguimos nele
dos aspectos [...], el texto literário y el texto espectacular; el primeiro se dirige a la
lectura, el segundo a la representación, pero ambos están en el texto escrito y en la
representación; el texto escrito todo está bajo expressión linguística; en la
representacion el texto literário se conserva en forma de palavra (diálogo
principalmente) e el texto espectacular en forma de signos verbales (diálogos) y no
verbales.

Relativamente à exploração do texto dramático, movemo-nos entre o jogo dramático, a improvisação e entre o trabalho em torno do texto teatral e a adaptação do texto literário a texto dramático, numa perspetiva que elegeu o ensaio e erro, o diálogo, a problematização e a contextualização como norteadores da ação pedagógica.

Chamamos à leitura e à cena os Contos da Mata dos Medos, de Álvaro de Magalhães, e as Histórias com Grilo Dentro, de António Torrado. Na antecâmara do encontro com o texto dramático, os jogos com as palavras e as suas sonoridades e as suas ressonâncias gestuais constituíram experiência acumulada, na medida em que estes alunos haviam já percorrido no primeiro ano, alguns dos trilhos da socialização à linguagem teatral.

Para estes alunos, já mais próximos do devir profissional, o conto configurou-se como porta de entrada no universo da educação de infância. A dinamização do conto passou inicialmente pela exploração da performance oral tendo como destinatários o universo escolar da infância. Numa fase posterior, o conto daria lugar à adaptação teatral e dramatização de um novo texto destinado ao trabalho com fantoches. 
Entendemos a exploração e dramatização de um texto como uma das formas de convocar e de usar a possibilidade que este encerra para ser jogado. Propusemos, mais uma vez, aos alunos jogar com as palavras, "fazer coisas" com as palavras, criar com e pela voz, comunicar e partilhar as próprias experiências, num espaço que, no fazer, se fez Teatro.

Antunes (2006) salienta que jogo dramático, enquanto fonte de novas experiências, estimula a compreensão, a expressão e a criação, podendo servir de indutor para a construção de um novo texto dramático.

Não se tratava, somente, de uma experiência analítica, intelectual, mas também da oportunidade dos alunos operarem em situações de resolução de problemas, em interação com os outros, na tomada de decisões, determinantes na conceptualização de espaços e criação teatral. Como refere Zich apud Bobes Naves (2004: 498):

\begin{abstract}
A linguagem verbal não é o único sistema de signos utilizado na obra dramática, nem necessariamente o mais destacado; na representação intervêm outros sistemas de signos entre os quais se cria uma tensão comunicativa muito diferente daquela que se dá na leitura; qualquer dos sistemas sémicos utilizados pode erigir-se no centro das referências para organizar o sentido da representação, da mesma maneira que na leitura de qualquer texto artístico.
\end{abstract}

Instigava-se, com a construção e animação do objeto "desanimado" - o fantoche -, novas relações com o corpo, com a leitura e com o mundo. Nos jogos de ocultação e revelação do corpo do "ator-marionetista", oferecia-se ao aluno a possibilidade de "não ser", para, sendo outro, ser mais ele na "anima" que insuflou na marioneta.

A invenção de lugares e atmosferas, a procura do recorte psicológico das personagens, a pesquisa dos diálogos e sua evolução, a apreensão de gradações psicológicas, a afinação da arte de surpreender ocupou parte significativa deste processo de criação teatral.

\title{
CONCLUSÕES
}

Neste primeiro ciclo de investigação-ação de um projeto, ele próprio in process, é prematuro avaliar o cumprimento global dos objetivos propostos, tanto mais que, em sentido absoluto, muitos deles só se materializarão no $3^{\circ}$ ano da licenciatura, a ter lugar no ano letivo de 2015/16. Nesta fase, importa enfatizar o facto do projeto, sobre o qual aqui se reflete, que é dar conta de uma filosofia de formação de futuros educadores de infância e docentes do $1^{\circ}$ ciclo do ensino básico que se alicerça em pressupostos como, entre outros, não apenas a necessidade premente de articulação interdisciplinar, mas também a relevância de uma formação cultural e artística verdadeiramente integradora. 
Tendo diagnosticado um conjunto significativo de fragilidades na formação literária e artística dos futuros professores/educadores, o projeto procura colmatar as lacunas que foram explicitadas e tornadas visíveis pelos resultados dos questionários.

Os registos diários do professor e dos alunos e as reflexões sistemáticas realizadas permitiram dar conta de uma evolução positiva, relativamente à compreensão da importância da relação entre a dimensão literária e performativa inerente à exploração do texto dramático, bem como à ampliação de significados atribuídos à experiência de educação literária e artística vivenciada.

O prazer da descoberta acústica da palavra, tanto na sua conformação narrativa, como poética, o reconhecimento do lugar que o corpo vivido detém no ato de ler e de dizer, a possibilidade da voz se transmutar e desmultiplicar na procura e interpretação de sentidos, bem como a consciência da necessidade de escuta e de procura da sua própria voz, como dizente, são, nesta fase da intervenção, os pontos mais referenciados nos comentários dos alunos do $1^{\mathrm{o}}$ ano.

Relativamente ao $2^{\circ}$ ano ganha significado a consciência de que os alunos parecem ter interiorizado relativamente à natureza espetacular e complexidade sígnica do texto teatral. A análise dos registos parece apontar para uma tomada de consciência dos alunos sobre a voz e o seu papel enquanto um dos elementos incontornáveis na performance literária oral.

Importa referir, ainda, nesta fase, dimensões de mudança nas conceções dos alunos materializadas em novas atitudes e gestos de abertura, como a pesquisa autónoma de obras/textos que pretendem ler; o interesse e envolvimento ativo manifestado na sua participação em ações e eventos de mediação literária; bem como na qualidade do seu desempenho performativo como diseurs, dimensão incontornável e inerente à sua futura identidade profissional.

\section{REFERÊNCIAS}

ANTUNES, C. A criação dramática: o fazer e o pensar: um estudo com futuros professores do $1^{0}$ ciclo do Ensino Básico, Tese de Doutoramento, Instituto de Estudos da Criança - Universidade do Minho, Portugal, 2006. Disponível em: $<$ http://hdl.handle.net/1822/7293>. Acesso em: 3 maio 2007.

BORTOLIN, S. Mediação Oral da Literatura: a voz dos bibliotecários lendo ou narrando. Thesis (Doutorado em Ciência da Informação) - Faculdade de Filosofia e Ciências, Universidade Estadual Paulista, Marília, 2010, 232 f. Disponível em: $<$ http://www.marilia.unesp.br/Home/PosGraduacao/CienciadaInformacao/Dissertacoes/bortol in_s_do_mar.pdfn>. Acesso em: 5 junho 2013. 
BOAL, A. Teatro do Oprimido e outras poéticas políticas. Rio de Janeiro: Civilização Brasileira, 1991.

BUESCU, H C. et al. Metas Curriculares de Português - Ensino Básico. Lisboa: Ministério da Educação, 2012.

CERRILLO, P. Los nuevos lectores: La formación del lector literario. p. 12 (texto impresso, 20 pp.), 2004. Disponível em: $<$ http://www.alonsoquijano.org/cursos2004/cursos\%202005/promocion_lectura/ponencia/Los $\% 20$ nuevos\%20lectores.\%20Pedro\%20Cerrillo.pdf $>$. Acesso em: 30 agosto 2005.

COMPAGNON, A. Para Que Serve a Literatura? Porto: Deriva, 2010.

FAZENDA, I. Práticas interdisciplinares nas escolas. S. Paulo: Cortez, 2001.

GOMES, J. A. Leitura, Literatura para a Infância e Bibliotecas Escolares. Vértice, nº 120, p. 5-21, novembro-dezembro 2004.

. Literatura para a infância e a juventude e promoção da leitura. Disponível no portal do Projeto Gulbenkian/Casa da Leitura, (s/d).

HERDEIRO, M. B. Dimensão pedagógica da leitura. AA.VV. Problemática da Leitura aspectos sociológicos e pedagógicos. Lisboa: INIC, p. 35-47, 1980.

KOUDELA, I. Jogos Teatrais. S. Paulo: Perspetivas, 1988.

LANDIER, J-C. \& BARRET, G. Expressão dramática e teatro. Porto: Edições ASA,1999.

LÓPEZ MOLINA, J. Por una educación literaria a partir de la LIJ. CLIJ - Cuadernos de Literatura Infantil y Juvenil, No 167, jan. 2004. p. 13.

MACEDO, A. C. \& GOMES, J. A. Educação Literária ( $1^{\circ}$ ciclo) e o lugar da escrita de Sidónio Muralha na formação de leitores. In: SILVA, M. M. M. C. T. da \& MOCIÑO, I. (Coord.). Literatura para a Infância e a Juventude e Educação Literária. Porto: Deriva, 2013. p. 73-91.

MARQUES, F. C. A Análise Literária. Coimbra: Livraria Almedina, 1972.

MATEO, P. EI Narrador Oral Y EI Imaginário. Guadalajara: Palabras del Cantil, 2010.

MENDOZA FILLOLA, A. EI Intertexto lector. El espacio de encuentro de las aportaciones del texto con las del lector. Cuenca: Ediciones de la Universidad de CastillaLa Mancha, 2001.

NAVES, B, M. Semiologia de la obra dramática. Madrid, Arco/Libros, 1997.

NAVES, B, M. Teatro Y Semiología. ARBOR. CLXXVII, 699-700, Marzo-Abril, p. 497-508, 2004. Disponível em: <http://arbor.revistas.csic.es>. Acesso em: 7 junho 2013.

ROIG RECHOU, B. A. Educación Literaria e Historias Literarias. In: A Mi Dizen Quantos Amigos EY - Homenaxe ao Professor Xosé Luís Couceiro. Santiago de Compostela: USC, 2008. pp. 33-342.

SILVA, M. M. M. C. T. \& MOCIÑO, I. (coord.). Literatura para a Infância e a Juventude e Educação Literária. Porto: Deriva, 2013.

SILVA, S. R. da (coord.) Do Livro à Cena. Porto: Deriva, 2009.

SPOLIN, V. Improvisação para o Teatro. S. Paulo: Perspetiva, 1992.

TURUEL, M. T.. Dinamización lingüística de textos teatrales: Que hacer con los textos teatrales en clase de lengua y literatura. In: MOTOS Turuel, Tomás (Coor.). Teatro y juego dramático. Barcelona: Graó, 1999. p.65-77.

VARLEY, J. Pedras d' água: bloco de notas de uma atriz do Odin Teatro. Ed. Teatro Caleidoscópio \& Editora Dulcina, 2011.

ZHUMTHOR, P. Introdução à poesia oral. S. Paulo: Hucitec, 1997. 